\title{
Thermal diffusivity measurement of zinc-aluminum-layered double hydroxide using photoflash technique
}

\begin{abstract}
The photoflash technique has been widely used for measuring thermal diffusivity of various types of materials. In this report thermal diffusivity of $\mathrm{Zn}-\mathrm{Al}$ layered double hydroxide synthesized at different ratios of $\mathrm{Zn}$ to $\mathrm{Al}$ composition is presented. The samples were prepared using $\mathrm{Zn}(\mathrm{NO} 3) 2$ and $\mathrm{Al}(\mathrm{NO} 3) 3$ solutions at $\mathrm{pH}$ of 10 by drop wise addition of $\mathrm{NaOH}$ solution with vigorous stirring under nitrogen atmosphere. Different compositions of $\mathrm{Zn}$ to $\mathrm{Al}$ molar ratios were obtained by changing the molar ratio of $\mathrm{Zn}(\mathrm{NO} 3) 2$ to $\mathrm{Al}(\mathrm{NO} 3) 3$. The slurry formed was kept at $70 \mathbb{P C C}$ in an oil bath shaker for $18 \mathrm{~h}$, filtered, washed and dried in an oven for $18 \mathrm{~h}$ at 70 PIC. A simple photo flash and polyvinlidene diflouride (PVDF) film was used as light source and thermal wave detector, respectively. Thermal diffusivity of $\mathrm{Zn}$ Al layered double hydroxide measure at room temperature was found increase with different compositions for $\mathrm{Zn}-\mathrm{Al}$ ratio of $3 \mathrm{I} 5$.
\end{abstract}

Keyword: PVDF; Thermal diffusivity; Zinc-aluminum layered double hydroxide; Flash technique 